\title{
Acute myeloid leukaemia with myelodysplasia-related change in a child living with human immunodeficiency virus infection, a transformation from underlying juvenile myelomonocytic leukaemia
}

\begin{tabular}{|c|c|}
\hline \multicolumn{2}{|c|}{$\begin{array}{l}\text { Authors: } \\
\text { Vongai Mashoko }{ }^{1,2} \text { (1) } \\
\text { Diane Mackinnon } \\
\text { Jenifer Vaughan } \\
\text { J,4 }\end{array}$} \\
\hline \multicolumn{2}{|c|}{$\begin{array}{l}\text { Affiliations: } \\
{ }^{1} \text { Department of Paediatrics } \\
\text { and Child Health, Faculty of } \\
\text { Health Sciences, University } \\
\text { of the Witwatersrand, } \\
\text { Johannesburg, South Africa }\end{array}$} \\
\hline \multicolumn{2}{|c|}{$\begin{array}{l}{ }^{2} \text { Department of Paediatrics, } \\
\text { Paediatric Oncology Unit, } \\
\text { Chris Hani Baragwanath } \\
\text { Academic Hospital, } \\
\text { Johannesburg, South Africa }\end{array}$} \\
\hline \multicolumn{2}{|c|}{$\begin{array}{l}{ }^{3} \text { Department of Molecular } \\
\text { Medicine and Haematology, } \\
\text { Faculty of Health } \\
\text { Sciences, University of the } \\
\text { Witwatersrand, Johannesburg, } \\
\text { South Africa }\end{array}$} \\
\hline \multicolumn{2}{|c|}{$\begin{array}{l}{ }^{4} \text { Molecular Medicine and } \\
\text { Haematology, National } \\
\text { Health Laboratory Services, } \\
\text { Johannesburg, South Africa }\end{array}$} \\
\hline \multicolumn{2}{|c|}{$\begin{array}{l}\text { Research Project Registration: } \\
\text { Project Number: M140158 }\end{array}$} \\
\hline \multicolumn{2}{|c|}{$\begin{array}{l}\text { Corresponding author: } \\
\text { Vongai Mashoko, } \\
\text { vdondo@yahoo.com }\end{array}$} \\
\hline \multicolumn{2}{|c|}{$\begin{array}{l}\text { Dates: } \\
\text { Received: } 05 \text { Sept. } 2020 \\
\text { Accepted: } 20 \text { Oct. } 2020 \\
\text { Published: } 17 \text { Dec. } 2020\end{array}$} \\
\hline \multicolumn{2}{|l|}{ Read online: } \\
\hline 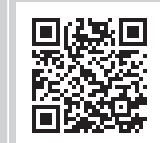 & $\begin{array}{l}\text { Scan this QR } \\
\text { code with your } \\
\text { smart phone or } \\
\text { mobile device } \\
\text { to read online. }\end{array}$ \\
\hline
\end{tabular}

Juvenile myelomonocytic leukaemia (JMML) is an aggressive clonal haematopoietic disorder that presents in early childhood. It is classified by the World Health Organization (WHO) as an overlap myeloproliferative or myelodysplastic disorder. The pathogenesis of JMML has been well-explained at the molecular level using clear diagnostic criteria. There is limited literature on JMML in the context of HIV infection. The only curative modality for the majority of patients with JMML is allogeneic haematopoietic stem cell transplant (HSCT). The role of other chemotherapeutic approaches is to ameliorate the disease but they are no substitute for allogeneic HSCT. We report a case of a 59-month-old child with vertically transmitted HIVinfection who was referred to the authors' institution for further management.

Keywords: paediatric oncology; leukaemias; myeloproliferative/myelodysplastic; JMML; HIV infection.

\section{Introduction}

Juvenile myelomonocytic leukaemia (JMML) is a clonal haematopoietic disorder of early

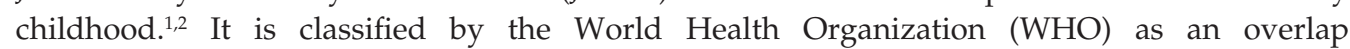
myeloproliferative or myelodysplastic disorder. ${ }^{3}$ Juvenile myelomonocytic leukaemia constitutes about $2 \%-3 \%$ of all childhood leukaemias. ${ }^{2}$ The incidence of JMML in South Africa is not known, as the published paediatric tumour registry combines all the leukaemias in one group. ${ }^{4}$ There is limited literature on JMML in a background of HIV infection. The only curative modality for the majority of patients affected with JMML is allogeneic haematopoietic stem cell transplant (HSCT) with an event free survival of $50 \%{ }^{2}$ We report a case of a 59 -month-old child who was managed at the authors' institution.

\section{Case report \\ Presentation}

A 59-month-old female child was referred to a tertiary-level care hospital in Gauteng, Johannesburg, South Africa with a history of epistaxis for 2 weeks. The child also had a longstanding history of abdominal distension.

The child was born at term with a normal birthweight. The mother tested HIV negative during pregnancy but seroconverted during breastfeeding. The child was diagnosed with HIV infection at 17 months of age following recurrent illnesses. She was commenced on first-line highly active antiretroviral therapy (HAART) (abacavir, lamivudine and lopinavir/ritonavir) and demonstrated good virological control. At the time of her presentation to our unit she was virologically suppressed.

\section{Physical examination}

The child was critically ill, pyrexial, tachypnoeic, tachycardiac and hypoxic (a condition that improved with supplemental oxygen). She was not dysmorphic but was severely underweightfor-age with moderate stunting and wasting. She had significant generalised lymphadenopathy

How to cite this article: Mashoko V, Mackinnon D, Vaughan J. Acute myeloid leukaemia with myelodysplasia-related change in a child living with human immunodeficiency virus infection, a transformation from underlying juvenile myelomonocytic leukaemia. S. Afr. j. oncol. 2020;4(0), a154. https://doi.org/10.4102/sajo.v4i0.154

Copyright: ( 2020. The Authors. Licensee: AOSIS. This work is licensed under the Creative Commons Attribution License. 
with the largest node in the left axilla, measuring 2 centimetres $(\mathrm{cm})$ in diameter. She had bounding pulses and auscultation revealed normal heart sounds with a grade $2 / 6$ systolic murmur at the apex. Crackles were heard in the left lower zone. The abdomen was distended with a $14 \mathrm{~cm}$ splenomegaly and $10 \mathrm{~cm}$ hepatomegaly. Neurologically, she was lethargic but had no focal neurological signs.

\section{Laboratory investigations}

The initial full blood count revealed a leukocytosis $\left(57.66 \times 10^{9} / \mathrm{L}\right)$, with a severe normocytic anaemia (haemoglobin 5.0 grams per decilitre $[\mathrm{g} / \mathrm{dL}]$, mean corpuscular volume (MCV) 85.9 femtolitre [fl]) and severe thrombocytopaenia (Platelet $8 \times 10^{9} / \mathrm{L}$ ). The differential count revealed a neutrophilia $\left(28.8 \times 10^{9} / \mathrm{L}\right)$ and a striking monocytosis $\left(9.22 \times 10^{9} / \mathrm{L}\right)$ with $12 \%$ blasts and promonocytes (blast equivalents), 5\% granulocyte precursors and 74 nucleated red blood cells / 100 white blood cells. Review of the peripheral smear revealed pseudopelgerisation of the neutrophils and significant dysplasia of the circulating erythroblasts (Figure 1). The lactate dehydrogenase was markedly elevated at $>2500$ units per litre (U/L). In addition, septic markers were also elevated with a C-reactive protein

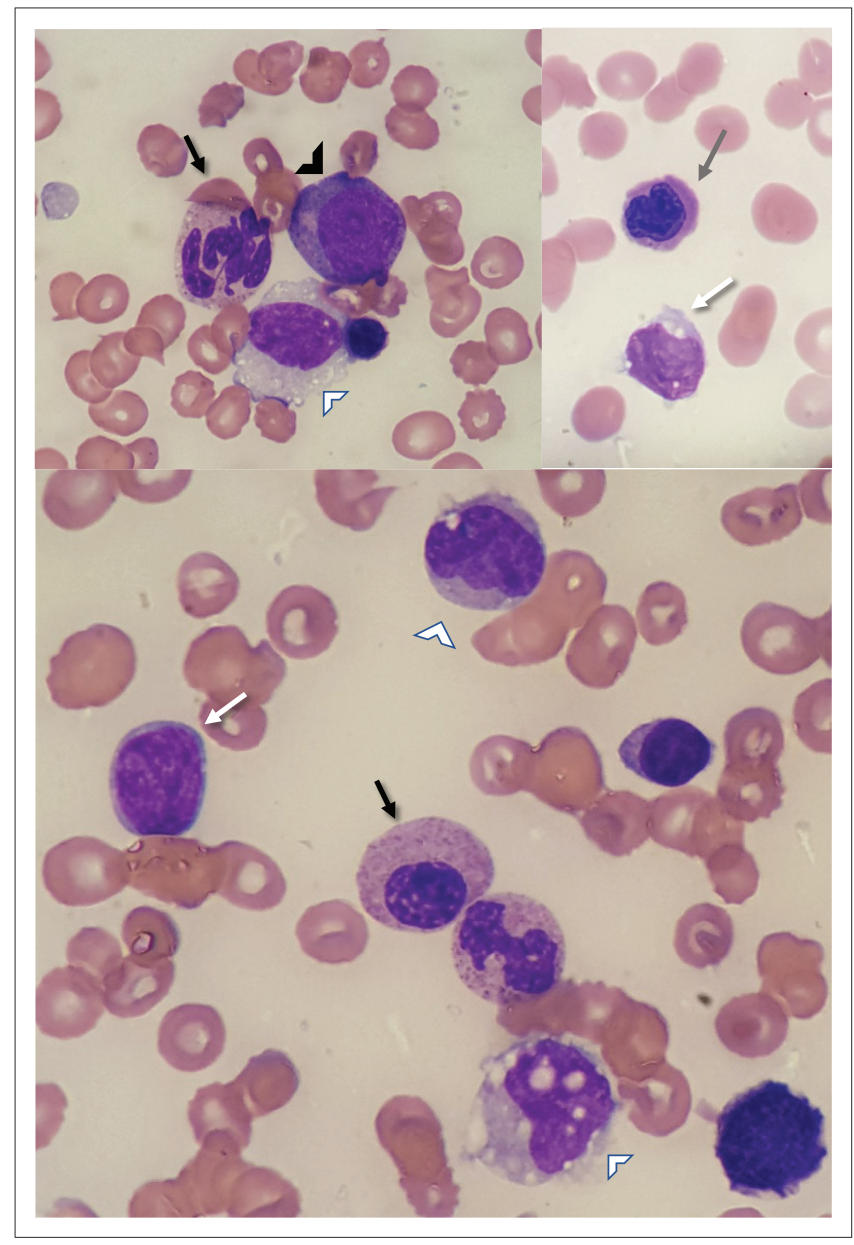

Note: Stained with May-GrünwaldGiemsa, $500 \times$ magnification.

FIGURE 1: Images from the peripheral blood showing disordered neutrophils (black arrows), blasts (white arrows), a granulocyte precursor (black arrowhead), monocytes (white arrow heads) and a dysplastic erythroblast. of 146 milligrams (mg)/L and procalcitonin of 15.9 microgram $(\mu \mathrm{g}) / \mathrm{L}$. There was no growth from blood cultures after 5 days of incubation. Serology for both cytomegalovirus and Epstein-Barr virus wase positive for IgG but negative for IgM. Bone marrow (BM) aspirate culture for Mycobacterium tuberculosis was also negative. The haemoglobin $\mathrm{F}(\mathrm{HbF})$ level was normal $(0.5 \%)$.

A BM aspirate revealed active, but disordered $(10 \%-50 \%)$ erythro- and granulopoiesis, with a reversed myeloid: erythroid ratio. Megakaryocytes were present, but underrepresented without striking dysplastic change. Blasts and blast equivalents comprised $18 \%$ of the cells present. Similar features were seen in the trephine biopsy, and blasts were seen to comprise $20 \%$ of the cells present on immunohistochemistry for CD34. Flow cytometry confirmed the blasts to be of myeloid lineage and demonstrated aberrant CD7 expression.

Fluorescent in situ hybridisation (FISH) analysis was positive for monosomy 7 , and negative for KMT2A rearrangement and the classical Philadelphia chromosome, $t(9 ; 22)$. Karyotypic analysis confirmed the presence of monosomy 7 in 10/13 metaphases, with a normal female karyotype in the remaining metaphases.

Next-generation sequence (NGS) revealed Tier I mutations in PTPN11 (variant allele frequency [VAF] 41.4\%), SETBP1 (VAF 43.1\%), ASXL1 (VAF 40.5\%) and a tier III mutation in STAG2 (VAF 55\%). Collectively, the results supported a diagnosis of acute myeloid leukaemia with myelodysplasiarelated change. This was suspected to have transformed from underlying JMML in view of the peripheral blood and clinical features together with the presence of the PTPN11 mutation detected on NGS.

\section{Progress}

Allogeneic HSCT is the only option that offers the child a chance for cure. The child does not have any siblings. In view of the massive hepatosplenomegaly resulting in respiratory compromise, she was put on metronomic therapy by using prednisolone and thioguanine as a bridging therapy whilst making arrangements with a transplant centre for HLA typing. Oral etoposide that is part of this therapy was not available. The organomegaly decreased to $5 \mathrm{~cm}$ splenomegaly and $8 \mathrm{~cm}$ hepatomegaly 2 months after starting the metronomic therapy. At 3 months the spleen was barely palpable. Platelet and red blood cell transfusion requirements have decreased from weekly to once a month. She was maintained on HAART.

\section{Ethical consideration}

The publication of case study reviews was carried out with permission and ethical clearance from the Human and Research Ethics Committee of the University of the Witwatersrand, reference number: M1906102. 


\section{Discussion}

Juvenile myelomonocytic leukaemia is a rare, aggressive haematopoietic disorder of infancy or early childhood caused by excessive production of cells of the monocytic and granulocytic lineages. ${ }^{1,2}$ The median age at presentation is 2 years. Males are more commonly affected as compared to females (male: female ratio 2-3:1). ${ }^{5,6}$ Patients usually present with fever, failure to thrive, thrombocytopenia, leucocytosis, splenomegaly, lymphadenopathy with or without respiratory symptomatology. This is a result of leukaemic infiltrates in the liver, spleen, lymph nodes and lungs. ${ }^{7}$ Although about $9 \%$ of children may present without splenomegaly, it usually becomes evident within weeks to a month of diagnosis. Gastrointestinal infiltrates may result in diarrhoea and cutaneous infiltrates result in non-specific lesions (including eczematous eruptions and indurated raised lesions). Leucocytosis is common, with a reported median white cell count of $35 \times 10^{9} / \mathrm{L}$ but white cell counts less than $10 \times 10^{9} / \mathrm{L}$ may occur. ${ }^{5,6}$ Examination of the peripheral smear usually reveals a neutrophilia and monocytosis, along with metamyelocytes, promyelocytes and immature monocytes. ${ }^{5}$ Bone marrow findings are non-specific, typically showing hypercellularity with a predominance of granulocytes during all stages of maturation. Dysplastic change is usually not prominent.

The diagnostic criteria are summarised in Box $1 .{ }^{2}$ Our patient met three of the four clinical and haematological criteria at presentation as she had a peripheral monocytosis, absolute count $>1000 / \mathrm{L}$, splenomegaly and absence of the breakpoint cluster region to Abelson (BCR-ABL1) fusion gene. However, her BM blast percentage was found to be $20 \%$ on trephine histology, which was speculated to represent JMML transformation. The $\mathrm{HbF}$ is usually elevated in cases of JMML associated with a normal karyotype. In our patient (who had monosomy 7), the $\mathrm{HbF}$ was normal.

More than $90 \%$ of patients with JMML show somatic or germline mutations in PTPN11, KRAS, NRAS, CBL or NF1 in their leukaemic cells. ${ }^{1,2,8}$ These mutations are mutually

BOX 1: Juvenile myelomonocytic leukaemia diagnostic criteria. ${ }^{2}$

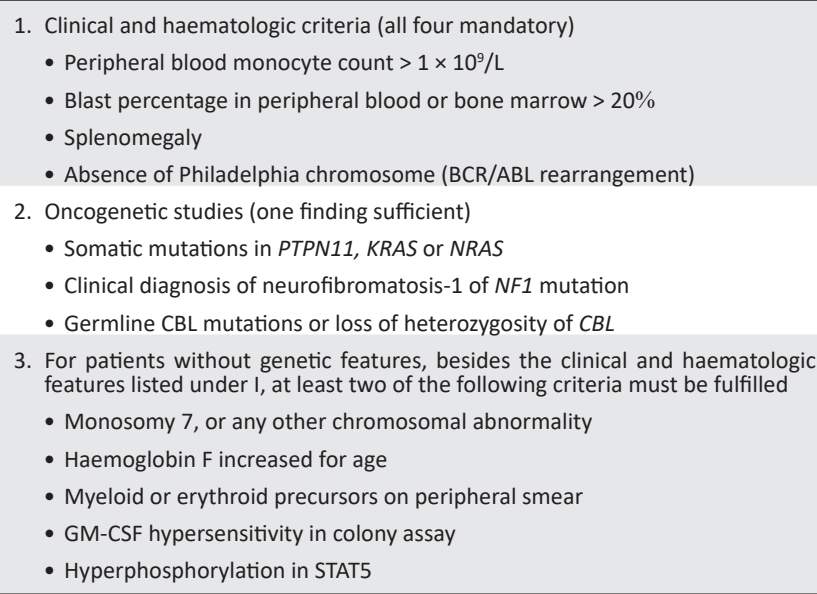

$\mathrm{BCR} / \mathrm{ABL}$, breakpoint cluster region to Abelson; GM-CSF, granulocyte-macrophage colonystimulating factor. exclusive, and they act by activating the RAS-signaling pathway. The germline mutations are sometimes termed RASopathies or neuro-cardio-facio cutaneous syndromes, ${ }^{2}$ with NF 1 and Noonan syndrome being the most frequently encountered. PTPN11 mutations are the most common in JMML, occurring in about $35 \%$ of patients, ${ }^{1}$ and have been shown to be associated with poorer disease outcomes compared to NRAS and CBL mutations ${ }^{1,2,9,10}$ (where spontaneous resolution of the haematologic abnormalities occasionally occurs ${ }^{2}$ ). The PTPN11 proto-oncogene encodes Src-homology tyrosine phosphatase 2 (SHP-2) a phosphatase that has a role in signal transduction and haematopoiesis through the RAS pathway. ${ }^{6,11}$

Our patient also had a SETBP1 mutation. This has been described in JMML where it is proposed to play a role in disease progression (rather than functioning as a driver mutation). ${ }^{2,9,12,13}$ SETBP1 mutations have been associated with poor outcome. . $^{1,9,14}$

Most patients with JMML (65\%) have a normal karyotype $\mathrm{e}^{5,15}$ whilst monosomy 7 and other abnormalities are found in $25 \%$ and $10 \%$ of cases, respectively. ${ }^{5}$

Allogeneic HSCT offers the best curative option with an event-free survival of about $52 \%{ }^{15}$ A case report of JMML on a background of vertically transmitted HIV, with successful HSCT has been published. ${ }^{16}$ In adults, the outcomes of HSCT in individuals living with HIV for other haematological malignancies have been found to be comparable to individuals not living with $\mathrm{HIV} .{ }^{17}$ Other chemotherapeutic approaches have limited role in JMML. 2,6 They may be used to ameliorate the disease but do not substitute allogeneic HSCT. They include 6-mercaptopurine and cytarabine ${ }^{10}$ as well as AML-type combination therapy. ${ }^{6}$ The use of 13-cis retinoic acid as a differentiating agent has been shown to reduce organomegaly and targeted therapy with monoclonal antibodies targeting various points in the RAS-signaling pathway including JAK3 inhibitors has been used in clinical trial settings. ${ }^{10}$ Spontaneous resolution has been described but is uncommon. ${ }^{18,19}$ Poor outcome is predicted by a lower platelet count $(<33000 / \mathrm{L})$, age $>2$ years at diagnosis and a high $\mathrm{HbF}(>40 \%)$ at presentation. 5

\section{Conclusion}

The pathogenesis of JMML has been well explained at the molecular level with clear diagnostic criteria. Next generation sequence testing is now available in South Africa making diagnosis easier. The only curative option is HSCT.

\section{Acknowledgements}

The authors thank the patient, the family and their institution for support during the management of this case.

\section{Competing interests}

The authors have declared that no competing interests exist. 


\section{Authors' contributions}

All authors contributed equally to this work.

\section{Funding information}

This research received no special grant from any funding agency in the public, commercial or not-for-profit sectors.

\section{Data availability statement}

Data sharing is not applicable to this article as no new data were created or analysed during this study.

\section{Disclaimer}

The views and opinions expressed in this article are those of the authors and do not necessarily reflect the official policy or position of any affiliated agency of the authors.

\section{References}

1. Niemeyer CM, Flotho C. Juvenile myelomonocytic leukemia: Who's the driver a the wheel? Blood. 2019;133(10):1060-1070. https://doi.org/10.1182/blood2018-11-844688

2. Locatelli F, Niemeyer $\mathrm{CM}$. How I treat juvenile myelomonocytic leukemia. Blood. 2015;125(7):1083-1090. https://doi.org/10.1182/blood-2014-08-550483

3. Arber DA, Orazi A, Hasserjian R, et al. Review Series the updated who classification of hematological malignancies. The 2016 revision to the World Health Organization classification of myeloid neoplasms and acute leukemia [homepage on the Internet]. 2016 [cited 2020 Jul 12]; Available from: https://ashpublications.org/ blood/article-pdf/127/20/2391/1393154/2391.pdf

4. Stefan DC, Stones DK. The South African paediatric tumour registry -25 years of activity. S Afr Med J. 2012;102(7):605-606.

5. Niemeyer CM, Aricó M, Basso G, et al. Chronic myelomonocytic leukemia in childhood: A retrospective analysis of 110 cases. Blood. 1997;89(10): 3534-3543.
6. Niemeyer CM, Kratz CP. Paediatric myelodysplastic syndromes and juvenile myelomonocytic leukaemia: Molecular classification and treatment options. $\mathrm{Br}$ Haematol. 2008;140(6):610-624. https://doi.org/10.1111/j.1365-2141.2007.06958.x

7. Aricò $M$, Biondi $A$, Pui $C H$. Juvenile Myelomonocytic Leukaemia. Blood. 1997;90(2):479-488

8. Jakovljević G, Kardum-Skelin I, Rogošić S, Nakić M. Juvenile myelomonocytic leukemia with PTPN11 mutation in a 23-month-old girl. Coll Antropol. 2010;34(1):251-254.

9. Miao $Y$, Li B, Ding L, et al. PTPN11 mutation with additional somatic alteration indicates unfavorable outcome in juvenile myelomonocytic leukemia: A retrospective clinical study from a single center. Eur J Pediatr. 2020;179(1): 463-472. https://doi.org/10.1007/s00431-019-03468-8

10. Chang TY, Dvorak CC, Loh ML. Bedside to bench in juvenile myelomonocytic leukemia: Insights into leukemogenesis from a rare pediatric leukemia. Blood. 2014;124(16):2487-2497. https://doi.org/10.1182/blood-2014-03-300319

11. Kratz CP, Niemeyer CM, Castleberry RP, et al. The mutational spectrum of PTPN11 in juvenile myelomonocytic leukemia and Noonan syndrome/myeloproliferative disease. Blood. 2005;106(6):2183-2185. https://doi.org/10.1182/blood-2005-02-0531

12. Sakaguchi $\mathrm{H}$, Okuno $\mathrm{Y}$, Muramatsu $\mathrm{H}$, et al. Exome sequencing identifies secondary mutations of SETBP1 and JAK3 in juvenile myelomonocytic leukemia. Nat Genet. 2013;45(8):973-941. https://doi.org/10.1038/ng.2698

13. Bresolin S, De Filippi P, Vendemini F, et al. Mutations of SETBP1 and JAK3 in juvenile myelomonocytic leukemia: A report from the Italian AIEOP study group. Oncotarget. 2016;7(20):28914-28919. https://doi.org/10.18632/oncotarget.8016

14. Stieglitz E, Troup CB, Gelston LC, et al. Subclonal mutations in SETBP1 confer a poor prognosis in JMML. Blood. 2015;125(3):516-524.

15. Locatelli F, No P, Zecca M, et al. Hematopoietic stem cell transplantation (HSCT) in children with juvenile myelomonocytic leukemia (JMML): Results of the EWOGMDS/EBMT trial Franco. 2005;105(1):410-419.

16. Dobson $G$, Klein N, Veys $P$, et al. Persistence of HIV reservoir following successful haematopoietic stem cell transplant for juvenile myelomonocytic leukaemia in a child with perinatally acquired HIV. J Virus Erad. 2019;5(3):e6-e9. https://doi. org/10.1016/S2055-6640(20)30048-0

17. Kuritzkes DR. Haematopoietic stem cell transplantation for HIV cure. J Clin Invest 2016;126(2):432-437. https://doi.org/10.1172/JCl80563

18. Matsuda K, Shimada A, Yoshida N, et al. Spontaneous improvement of hematologic abnormalities in patients having juvenile myelomonocytic leukemia with specific RAS mutations. Blood. 2007;109(12):5477-5480. https://doi.org/ 10.1182/blood-2006-09-046649

19. Flotho C, Kratz CP, Bergstra E. To the editor: Genotype-phenotype correlation in cases of juvenile myelomonocytic leukemia with clonal response. Blood. 2008;111(2):2007-2008. 